\title{
Design de produto para o espaço urbano: bebedouro público
}

\section{Product design for the urban space: public drinking} fountain

Bruno Spanevello Pergher ${ }^{1}$

Fabiane Vieira Romano ${ }^{2}$ 


\section{Resumo}

Este trabalho teve como objetivo geral, desenvolver um bebedouro público que fornecesse água potável de maneira adequada para uma população diversificada. Foram aplicados os conhecimentos adquiridos no curso de Desenho Industrial - Projeto de Produto da UFSM através de um método de projeto elaborado especificamente para este trabalho, que inclui as fases de Projeto Informacional, onde o problema é analisado para definir os Requisitos do Projeto tais como, ser acessivel a pessoas de diferentes alturas e cadeirantes, a possibilidade de encher garrafas de maior volume, entre outros; Projeto Conceitual, onde são geradas possiveis soluções para o problema; Projeto Preliminar, onde a melhor alternativa é refinada e Projeto Detalhado que compreende a apresentação e documentação necessária do projeto e a produção do modelo para testes. Como resultado obicônica, que atende sem distinção a maior parte da população, oferecendo ainda a possibilidade de encher copos e garrafas e que pode ser instalado em diversos espaços públicos das cidades.

Palavras-Chave: Desenho Industrial; Design Urbano; Bebedouro Público. teve-se um bebedouro com identidade

\section{Abstract}

This work aimed to develop a public drinking fountain that provides drinking water appropriately for a diverse population. Knowledge were applied acquired in the course of Industrial Design of UFSM through a design method specifically designed for this work, which includes the steps of Informational Project, where the problem is analyzed to define the project requirements such as being accessible to people of different heights and wheelchair users, the possibility to fill a larger volume bottles, among others; Conceptual Project, which are generated possible solutions to the problem; Preliminary Project, where the best alternative is refined and Detailed Project comprising the presentation and documentation required the design and production of the model for testing. As a result we obtained a drinking fountain with iconic identity that caters equally to most of the population, still offering the possibility to fill cups and bottles and that can be installed in various public spaces of cities.

Keywords: Industrial Design; Urban Design; Drinking Fountain.

ISSN: 1808-3129

\footnotetext{
${ }^{1}$ Universidade Federal de Santa Maria RS, Brasil bruno.pergher@terra.com.br

${ }^{2}$ Universidade Federal de Santa Maria

RS, Brasil

fabiromano@gmail.com
}

Artigo indicado através da organização do evento IDEMi 2015 


\section{INTRODUÇÃO}

Analisando os produtos que diariamente utilizamos nos damos conta de que muitos deles podem ser melhorados. Nos deparamos com objetos dentro e fora de casa que nos causam desconforto ou que não cumprem com a função prometida. No papel de designers, cresce todos os dias a vontade de criar algo melhor.

O problema é que ao contrário dos produtos que adquirimos para uso privado, para alguns objetos não nos é dado um poder de escolha e assim somos obrigados a utilizar algo que por vezes nos incomoda. Esse é o caso do mobiliário e equipamentos urbanos.

Não faltam exemplos em nossos centros urbano de paradas de ônibus, lixeiras, bancos, canteiros, etc., que ou não foram pensados adequadamente, não satisfazendo as necessidades dos usuários de forma correta, ou estão com sua função comprometida por estarem depredados ou ainda, são inexistentes. Este último foi uma das motivações para escolha do produto a ser projetado neste trabalho.

Atualmente a cidade de Santa Maria, RS não possui uma solução apropriada para seus habitantes se hidratarem enquanto usufruem de ambientes como praças e parques ou apenas circulam pelo espaço público urbano. Um produto para este fim seria de grande utilidade na cidade que todos os anos tem verões com temperaturas que chegam a ultrapassar os $40^{\circ} \mathrm{C}$.

Pensando neste problema decidiu-se que se projetaria um bebedouro público para a cidade "Coração do Rio Grande", Santa Maria.

Com base em um método de projeto específico para este projeto, buscou-se informações úteis e diversas, através de revisão de literatura, que auxiliaram na construção dos requisitos de projeto que nortearam a geração, análise e escolha de alternativas que detalhadas e configuradas passaram para a produção do modelo que tem como objetivo apresentar o produto e validar os requisitos, sejam eles funcionais, ergonômicos, formais e estruturais.

Legitimando a importância de um bom projeto para o ambiente urbano Teixeira [1] diz que "é notória uma relação profunda entre espaço e sociedade - a qualidade do ambiente no qual trabalhamos, moramos, passeamos e nos divertimos influencia determinantemente a qualidade de vida de cada um de nós".

Transformar a cidade para melhor, resolver os seus problemas, mudar a sua cara. Essa sempre foi uma inquietação de muitos designers, em especial dos autores deste trabalho, pois os benefícios de um objeto projetado adequadamente afetam diretamente os utilizadores (habitantes ou não) do local e obviamente neste vasto "público alvo" estão também os próprios designers.

O designer tem as ferramentas necessárias para interferir positivamente no visual, conforto e segurança de produtos utilitários, oferecendo maior qualidade de vida principalmente ao cidadão comum, aquele que utiliza diariamente os serviços públicos e acaba se deparando com produtos muitas vezes inadequados para atender as suas necessidades. Através da criação de um bebedouro público, hoje inexistente em Santa Maria, espera-se atender à necessidade da população de saciar a sede enquanto se desloca pelo espaço urbano da cidade.

Com este trabalho, ainda pretende-se incentivar, mesmo que implicitamente, o 
porte e utilização diária de garrafas d'água individuais para hidratação, assim reduzindo o lixo gerado pelo descarte de garrafas plásticas que não são reutilizadas.

Teixeira (2010) esclarece que "através da adoção de soluções formais e funcionais, o desenho deve permitir a resolução de problemas de natureza biofísica (clima, orografia, tipo de solo, flora, fauna, entre outros), econômica e social. Estes aspectos de ordem formal e funcional interferem na leitura que se retira dos espaços, sendo através das suas características próprias que se torna possível a sua identificação e reconhecimento, destacando-o da malha urbana envolvente".

"O mobiliário urbano cumpre funções tão importantes nos espaços públicos das cidades que sua ausência é imediatamente percebida pelas pessoas. Na verdade, sua ausência pode transformar uma visita a um lugar em uma experiência incômoda, muitas vezes fazendo com que não tenhamos vontade de voltar", conta Baratto (2013).

\section{METODOLOGIA}

O método de projeto definido para este trabalho (Figura 1) foi baseado na sistematização de processos apresentada por Romano (2003), assim sendo divido em Pré-projetação e Projetação e composto por ferramentas de Bonsiepe (1984), Löbach (2001) e outros autores.

"Como o processo de design pode se desenvolver de forma extremamente complexa (dependendo da magnitude do problema) nos parece útil, para fins didáticos, dividi-lo em [...] fases distintas, embora estas fases nunca sejam exatamente separáveis no caso real. Elas se entrelaçam umas às outras, com avanços e retrocessos", conforme Löbach (2001). Então mesmo que na prática está separação não seja tão exata, isso facilita a organização das etapas e sugere rumos para o projeto.

Lembrando que segundo observação de Bonsiepe (1984), metodologia não tem finalidade em si mesmo, é só uma ajuda no processo projetual; dá uma orientação no procedimento do processo (macroestrutura, fases, etapas) e oferece técnicas, métodos que podem ser usados em certas etapas (microestrutura).

A metodologia sendo uma orientação com avanços e retrocessos, e não um processo fechado e linear, pode sofrer alterações ao longo do tempo de acordo com as necessidades do projeto em questão. 


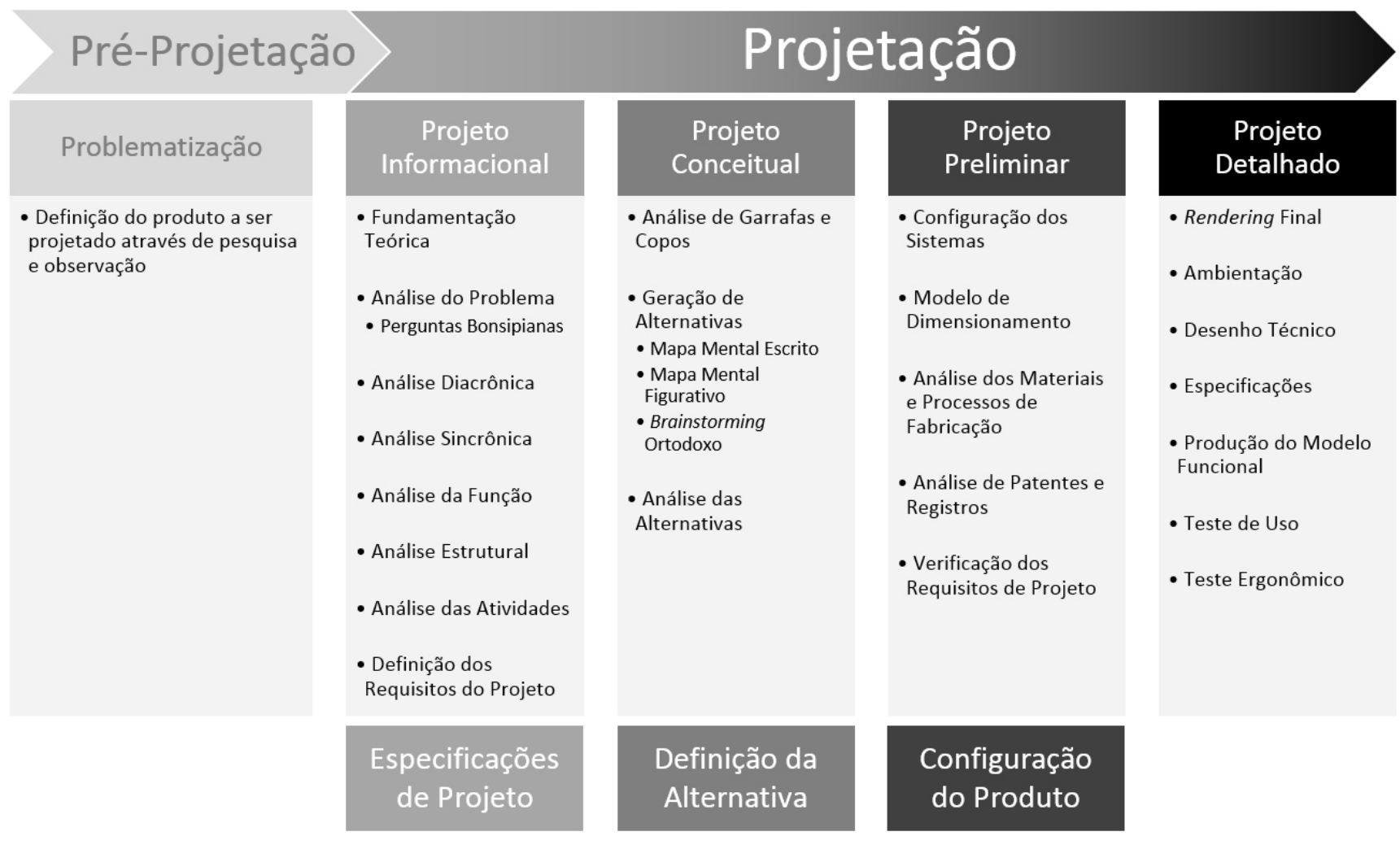

Figura 1 - Método de Projeto

\section{DESENVOLVIMENTO}

Iniciando a Projetação, segundo Löbach (2001), “o Projeto Informacional é muito importante para recolher todas as informações que se possa conseguir e prepará - las para a fase posterior de avaliação. Para isto é essencial a coleta de conhecimentos sobre o problema sem censuras. Todos os dados podem ser importantes, para a base sobre a qual se construirá a solução".

Alguns assuntos guiaram as pesquisas e ajudaram no entendimento do contexto do projeto. Primeiramente buscou-se informações sobre temas mais amplos como "O Ambiente Construído", "Design em Espaços Públicos", "Os Espaços Abertos e o Design Universal" e "Ciclo de Vida de Produtos". Em seguida, os tópicos, "Mobiliário Urbano" e "Identidade Santa-mariense", foram mais direcionados ao projeto de produto para as cidades, especificamente para o município de Santa Maria.

Como fonte de inspiração, bons projetos de produtos e intervenções urbanas, nacionais e internacionais serviram para ampliar os horizontes da criatividade.

Além disso, buscou-se compreender os fatos importantes da criação e evolução do produto "bebedouro" na história (Análise Diacrônica).

E da análise do que existe hoje em matéria de bebedouro (Análise Sincrônica), puderam ser identificados elementos úteis ao projeto e que não configurassem cópia ou imitação.

As atividades realizadas pelos usuários para utilizar um bebedouro, seja para beber água ou encher garrafas, foram observadas e mapeadas (Figura 2) para entender seus comportamentos. Com isso, pode-se reduzir erros e confusões na interface do produto a ser desenvolvido. 
Visualizar o bebedouro
Ir até o

bebedouro
Identificar o acionador e

a saida de água
Aproximar a mão

do acionador
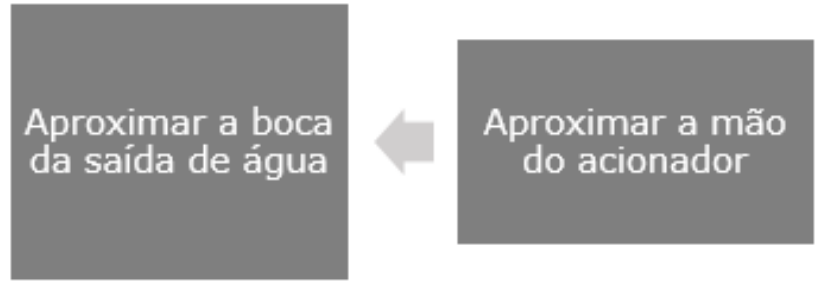

Apoiar-se na

estrutura

BEBER ÁGUA

Soltar o acionador para interromper o fluxo de água

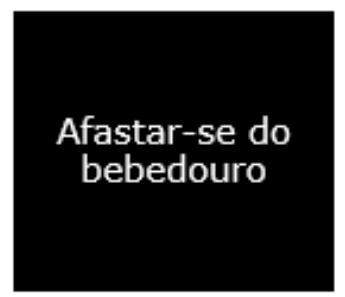

Figura 2 - Análise da atividade do usuário ao beber água em um bebedouro.

Como última análise, estudaram-se diferentes tipos de copos e garrafas encontradas hoje no mercado (Figura 3), quanto as suas dimensões para futuramente projetar o sistema de enchimento do bebedouro. 


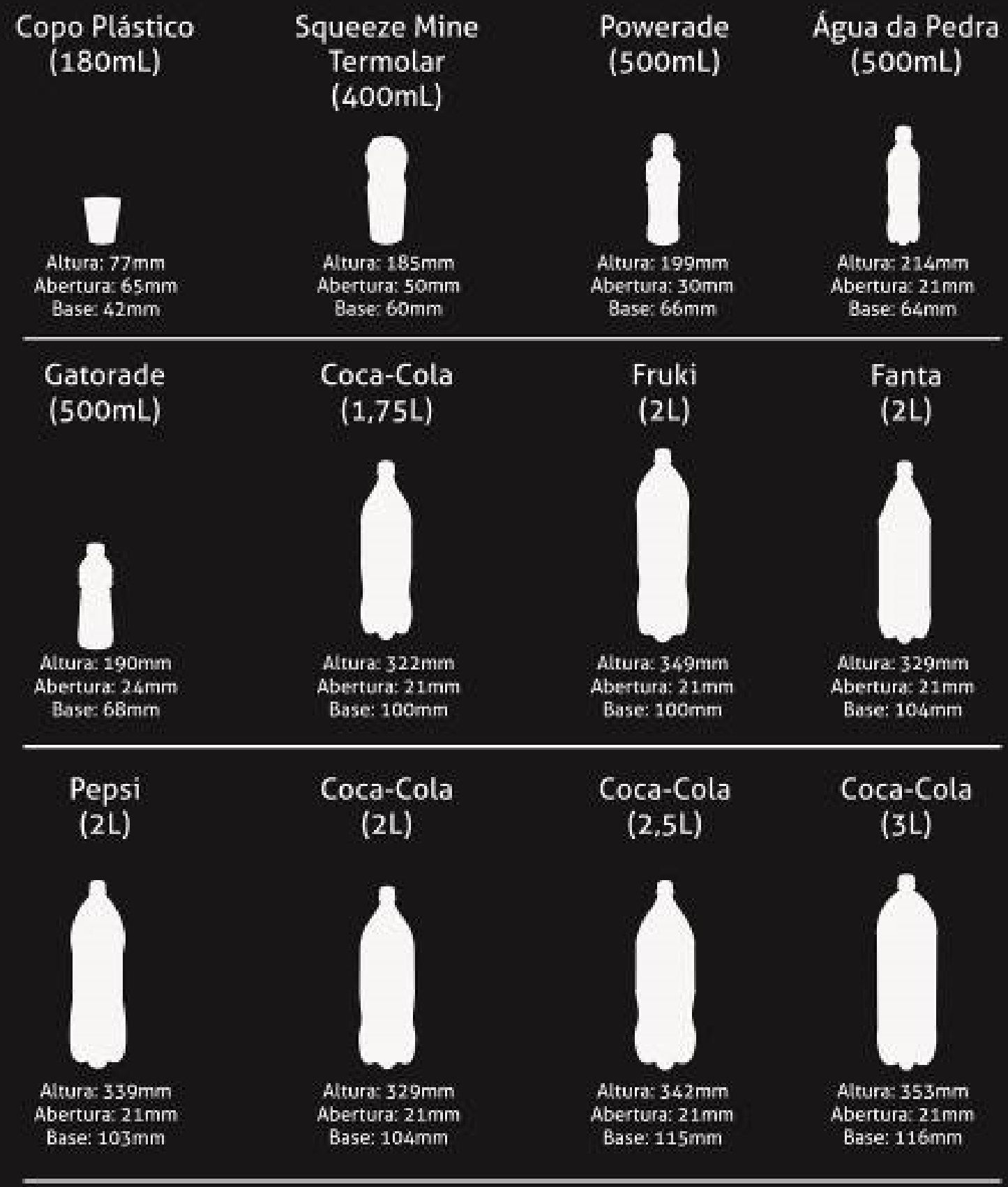

Pepsi

$(3,3 \mathrm{~L})$

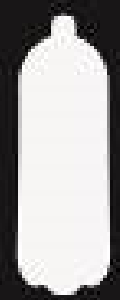

Alturo: $350 \mathrm{~mm}$

Abertura: $21 \mathrm{~mm}$

Base: $120 \mathrm{~mm}$

Figura 3 - Diferentes garrafas foram estudadas para o futuro sistema de enchimento do bebedouro. 
Todos os dados recolhidos foram utilizados para gerar os Requisitos do Projeto (Figura 4) que deveriam ser cumpridos para a solução completa do problema em questão.

\begin{tabular}{|l|l|}
\hline \multirow{5}{*}{ Requisitos Funcionais } & Saída de água única para adultos, crianças e cadeirantes. \\
\cline { 2 - 2 } & Possibilidade de enchimento de copos e garrafas de até 2 litros sem precisar segurar a garrafa. \\
\cline { 2 - 2 } & Pouca ou nenhuma manutenção (Facilidade de Manutenção). \\
\cline { 2 - 2 } & Mecanismos devidamente dispostos e sinalizados para usuários inexperientes (Facilidade de Uso). \\
\cline { 2 - 2 } & Baixo custo de produção. \\
\cline { 2 - 2 } Requisitos Ergonômicos & Ser seguro durante o uso. \\
\cline { 2 - 2 } & Saída de água em parábola. \\
\hline \multirow{5}{*}{ Requisitos Formais } & Acessível a pessoas de diferentes alturas e cadeirantes (ABNT/NBR 9050). \\
\cline { 2 - 2 } & Possibilidade de apoio do corpo. \\
\hline & Aparência que transpareça segurança e limpeza. \\
\cline { 2 - 2 } Requisitos Estruturais & Adequado a diversos espaços públicos. \\
\cline { 2 - 3 } & Forma atemporal. \\
\cline { 2 - 2 } & Forma aliada à função. \\
\hline & Mecanismos hidráulicos composto por peças padronizadas facilmente encontradas no mercado. \\
\cline { 2 - 2 } & Ser resistente às intempéries. \\
\cline { 2 - 2 } & Ser resistente no momento do uso. \\
\hline
\end{tabular}

Figura 4 - Especificações/Requisitos do projeto estipulados com base nas informações obtidas no Projeto Informacional.

O Projeto Conceitual é a fase destinada à geração de alternativas de solução para o problema em questão. Como disse Baxter (2000), a geração de ideias é o coração do processo criativo. E dentre as inúmeras técnicas existentes que auxiliam no processo criativo selecionou-se o Mapa Mental (Figura 6) como ferramenta inicial e antecedente à Geração de Alternativas de fato. Os mapas mentais são utilizados para representar a estrutura conceitual de um indivíduo sobre um determinado assunto, de forma visual, escrita e figurativa.

O Mapa Mental é um recurso que canaliza a criatividade, porque utiliza todas as habilidades a ela relacionadas, sobretudo "a imaginação, a associação de ideias e a flexibilidade", conforme Moscatelli (2013).

Tendo em mãos os mapas mentais e as diversas análises anteriores, iniciou-se, em um caderno não pautado, a geração livre de alternativas ou brainstorming ortodoxo com a realização de modelagem bi e tridimensional, em grande quantidade e sem censura, "com explícita proibição de formular observações críticas" (BONSIEPE, 1984) quanto à viabilidade de produção e futuro das formas ali esboçadas.

Alguns autores acreditam que a esta técnica pode ser aplicada a máxima "quantidade gera qualidade", pois quanto maior o número de alternativas geradas, em tese, maior a possibilidade, durante a avaliação das mesmas, de encontrar aquela que solucione o problema em questão com maior eficácia.

Todas as alternativas foram então analisadas, selecionadas (Figura 5) e delas foi escolhida a melhor alternativa dentro de alguns critérios. 


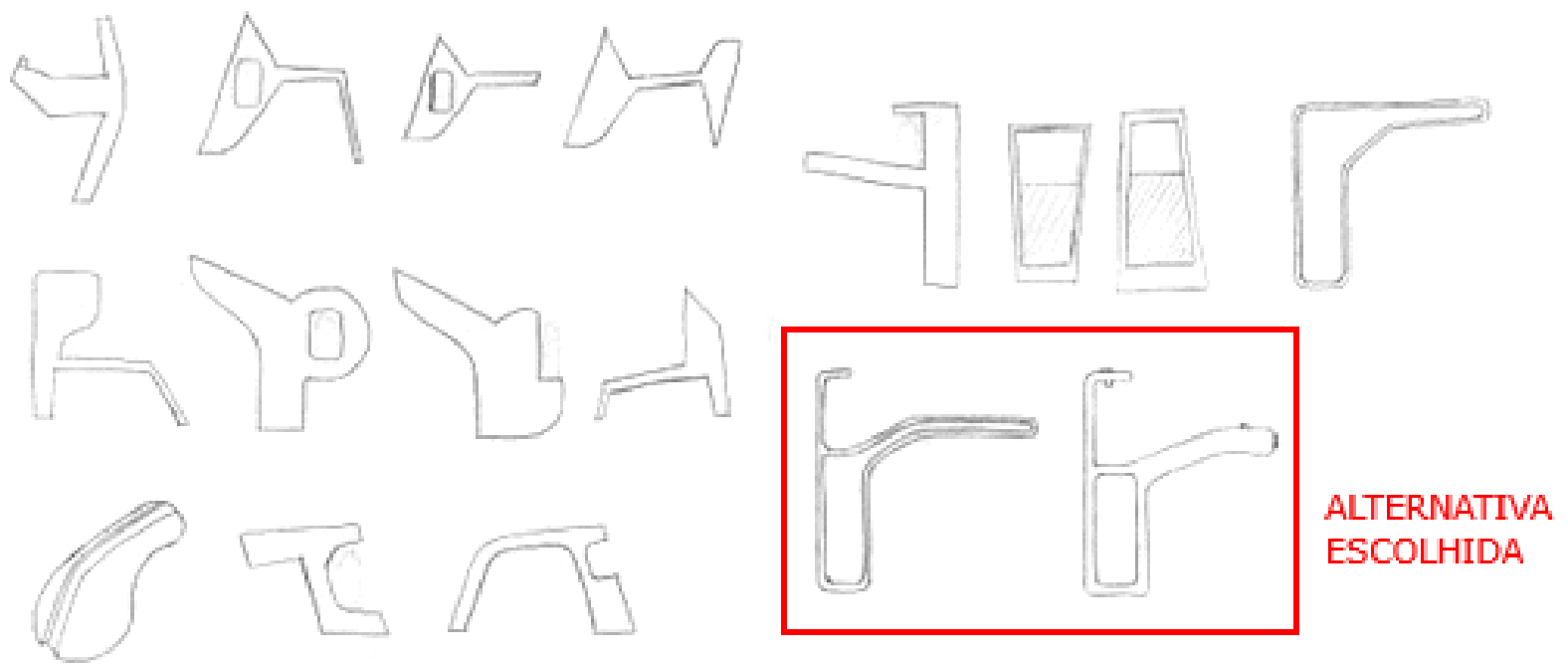

Figura 5 - Alternativas selecionadas para análise e definição da solução definitiva.

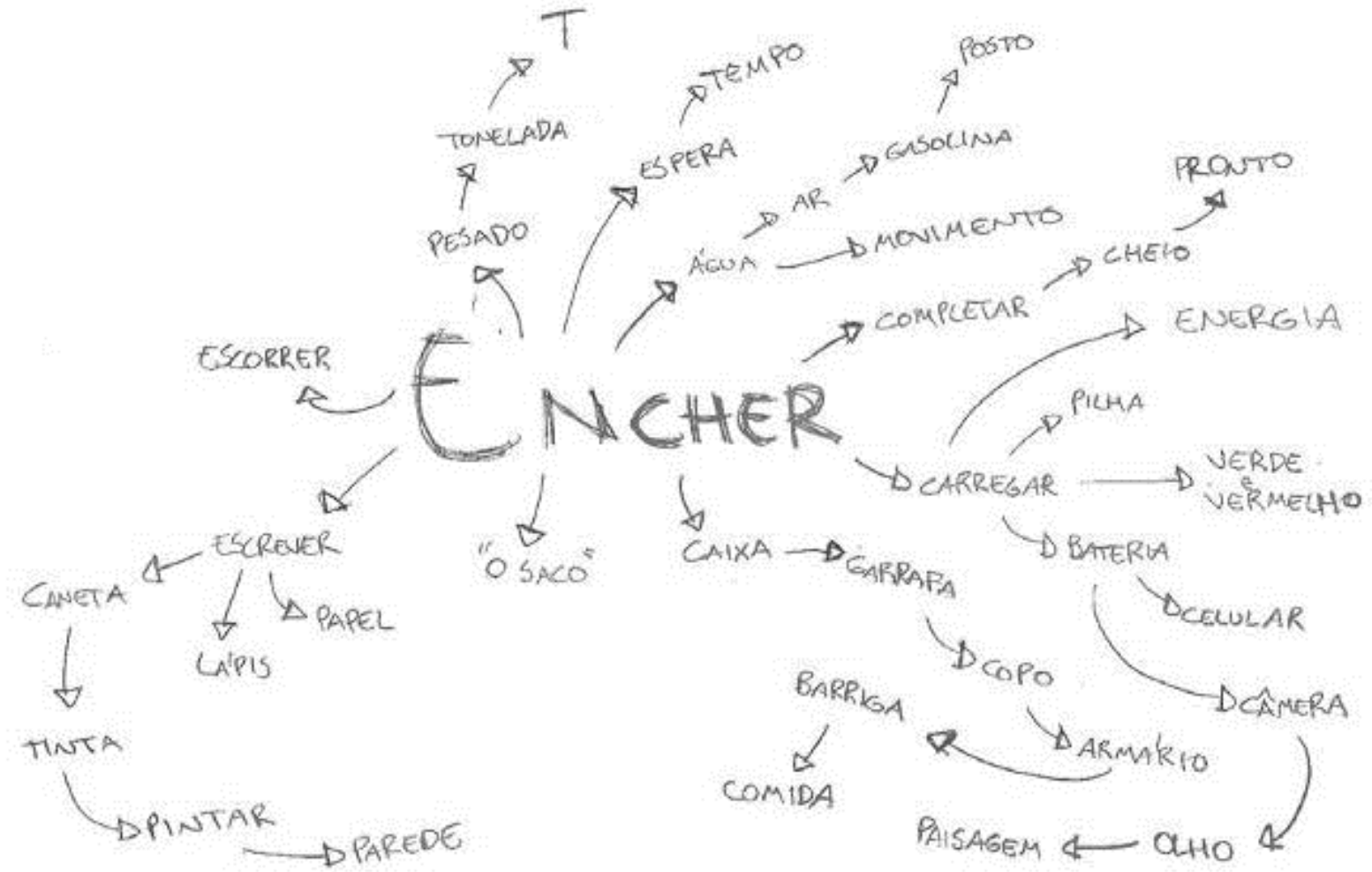




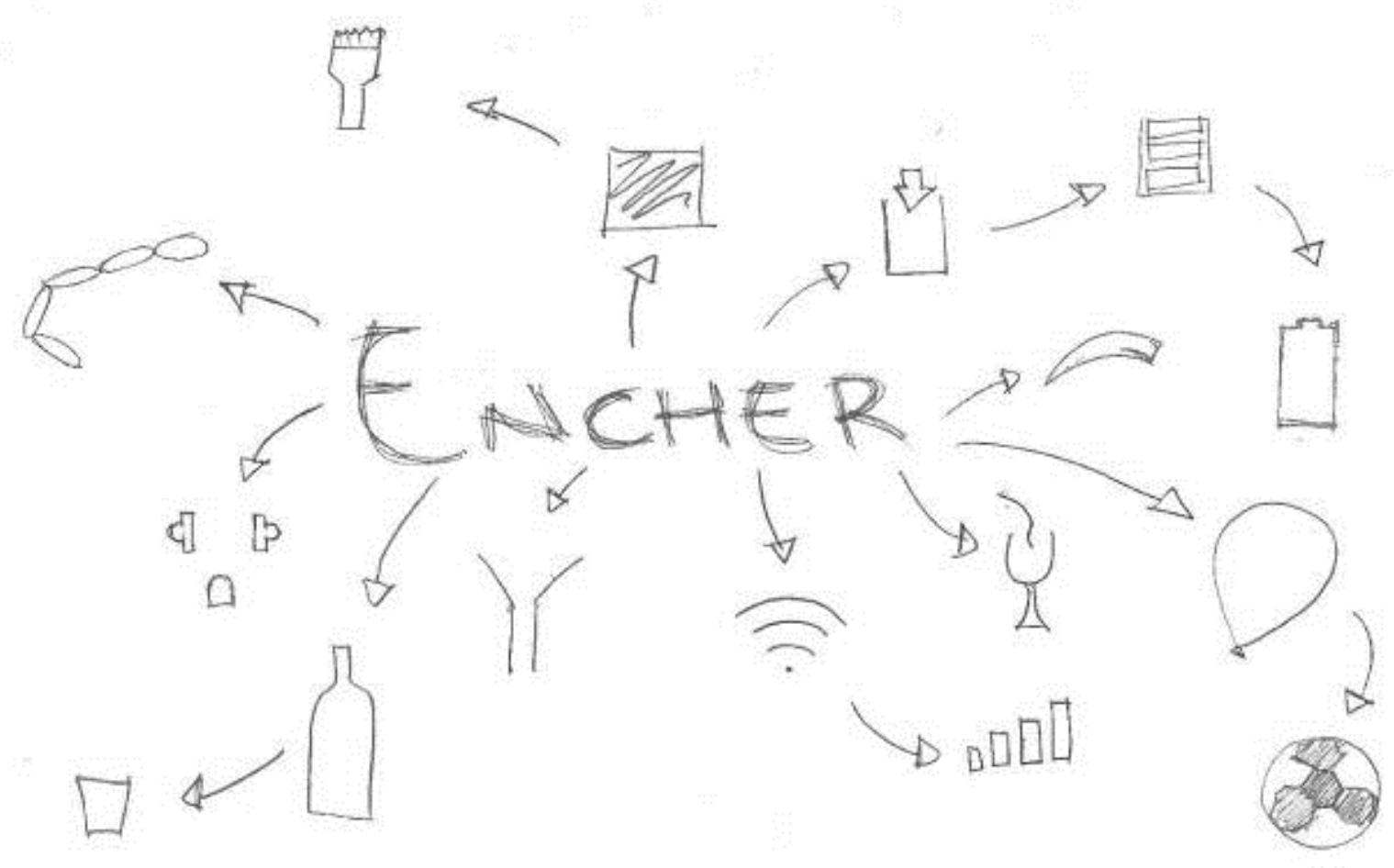

Figura 6 - Exemplos dos mapas mentais criados.

No Projeto Preliminar mais alguns estudos foram realizados para a escolha das matérias primas a serem utilizadas no produto, bem como os processos de fabricação possíveis.

A proposta de solução escolhida foi então configurada em detalhes e para tal foi confeccionado um modelo de papelão em tamanho real (Figura 7) para melhor visualizar os ajustes necessários na forma. Também foram definidos os parâmetros do sistema hidráulico (Figura 8) e acabamentos para atender às normas nacionais, definir a sua produção e adequá-lo conforme as especificações do projeto. 


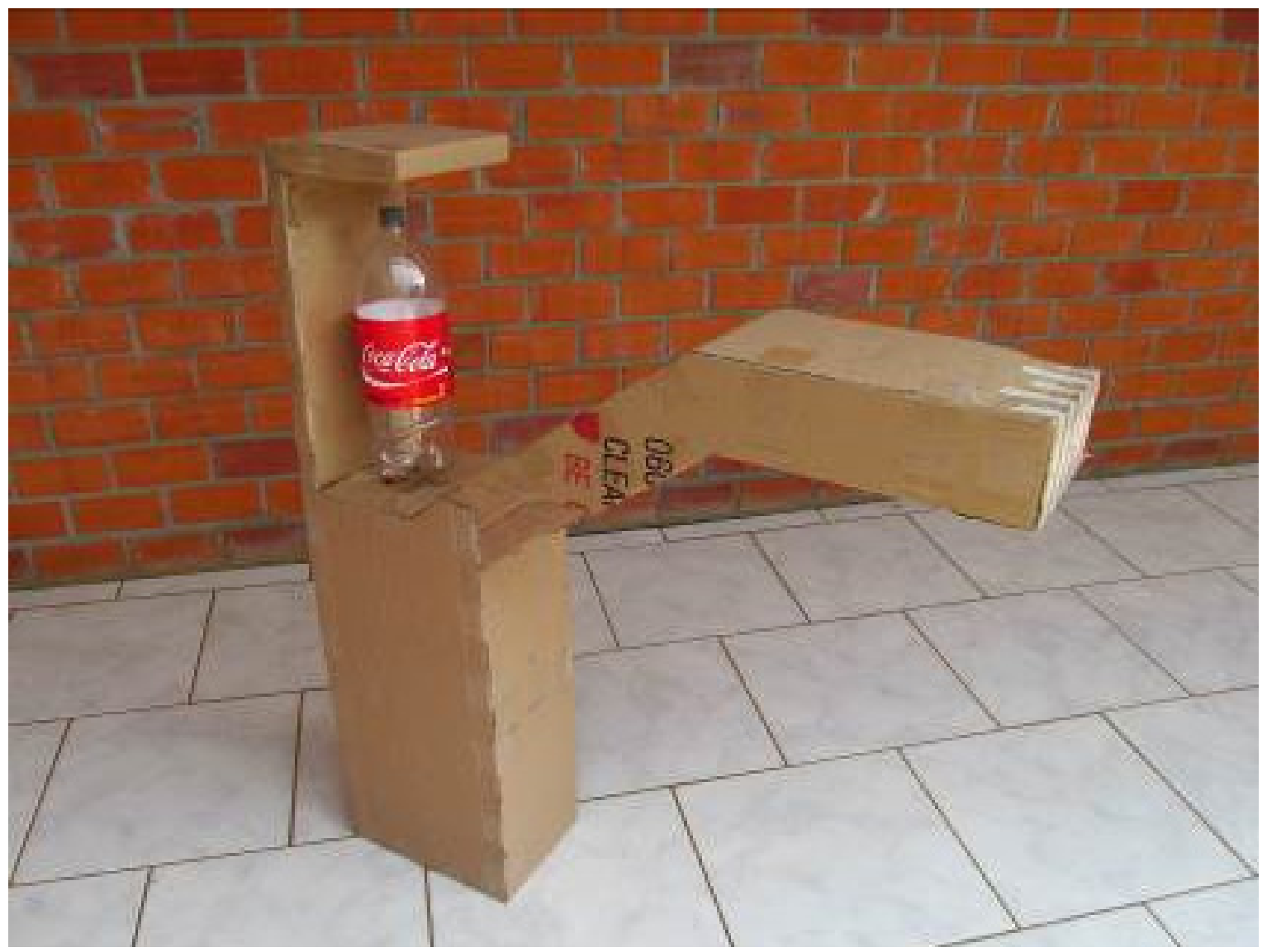

Figura 7 - Modelo em papelão utilizado para adequar as dimensões do produto.

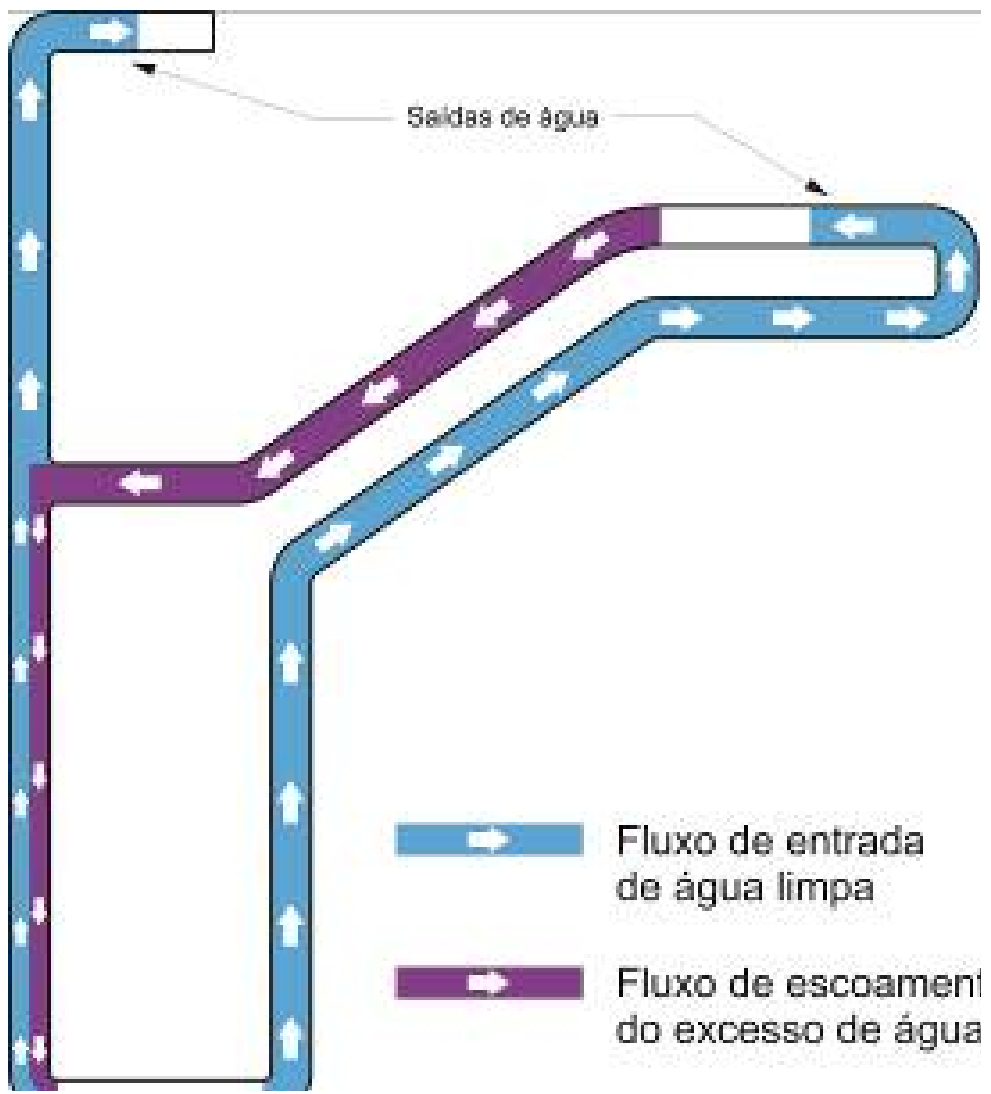

Figura 8 - Esquema dos fluxos de entrada e saída de água no bebedouro. 
Para garantir que o produto desenvolvido é diferente de outros já projetados, produzidos ou que já estão no mercado, foi realizada uma pesquisa de patentes e registros de Desenho Industrial de bebedouros em alguns países. Esta investigação é importante, pois um dos objetivos do trabalho é desenvolver um produto único passível de registro de Desenho Industrial.

Segundo definição do Instituto Nacional da Propriedade Intelectual (INPI, 2014), o registro de Desenho Industrial protege a forma externa ornamental de um objeto ou o conjunto de linhas e cores aplicado a um produto, desde que apresentem um resultado novo e original e que seja passível de produção industrial. Este tipo de registro não protege funcionalidades, dimensões, materiais utilizados ou processos de fabricação de um objeto. A legislação brasileira prevê a proteção de até 20 objetos por pedido desde que as variantes apresentadas mantenham as mesmas características distintivas preponderantes. O registro de Desenho Industrial concedido confere ao titular, propriedade temporária sobre o Desenho Industrial e o direito de excluir terceiros de fabricação, comercialização, uso, venda e etc. sem sua prévia autorização, em território nacional.

A pesquisa de patentes e registros foi realizada por meio do software Orbit v1.8.4, acessado pelo site Orbit.com. O software realiza buscas em bases internacionais a procura de registros que possuam os parâmetros de pesquisa definidos pelo usuário.

Buscou-se no software registros que possuíssem imagens para serem analisadas. A busca foi realizada no dia 11 de Abril de 2014 a partir do termo Bebedouro, sem distinção de uso público ou privado, mas não foi encontrado nenhum resultado, então utilizou-se traduções do termo como Drinking Fountain em inglês, localizando assim 110 resultados. Depois o termo em espanhol, Fuente, com 31 registros localizados referentes a produtos com função para beber ou encher garrafas. $O$ termo alemão Trinkbrunnen retornou 5 resultados com imagens e em francês, Fontaine, aproximadamente 1000.

Confirmando a originalidade deste projeto, não foi encontrada nenhuma referência clara quanto à forma do produto em nenhum dos registros localizados.

Por fim, executou-se o Projeto Detalhado onde foram criados todos os documentos necessários para a fabricação do produto de maneira industrial tais como, memorial descritivo e desenhos técnicos e, no caso deste trabalho, nesta fase também foi construído, na marcenaria do curso de Desenho Industrial da UFSM (Figura 9 e Figura 10), o modelo final funcional em MDF para testes e exposição, com o auxílio de dois técnicos da área. 


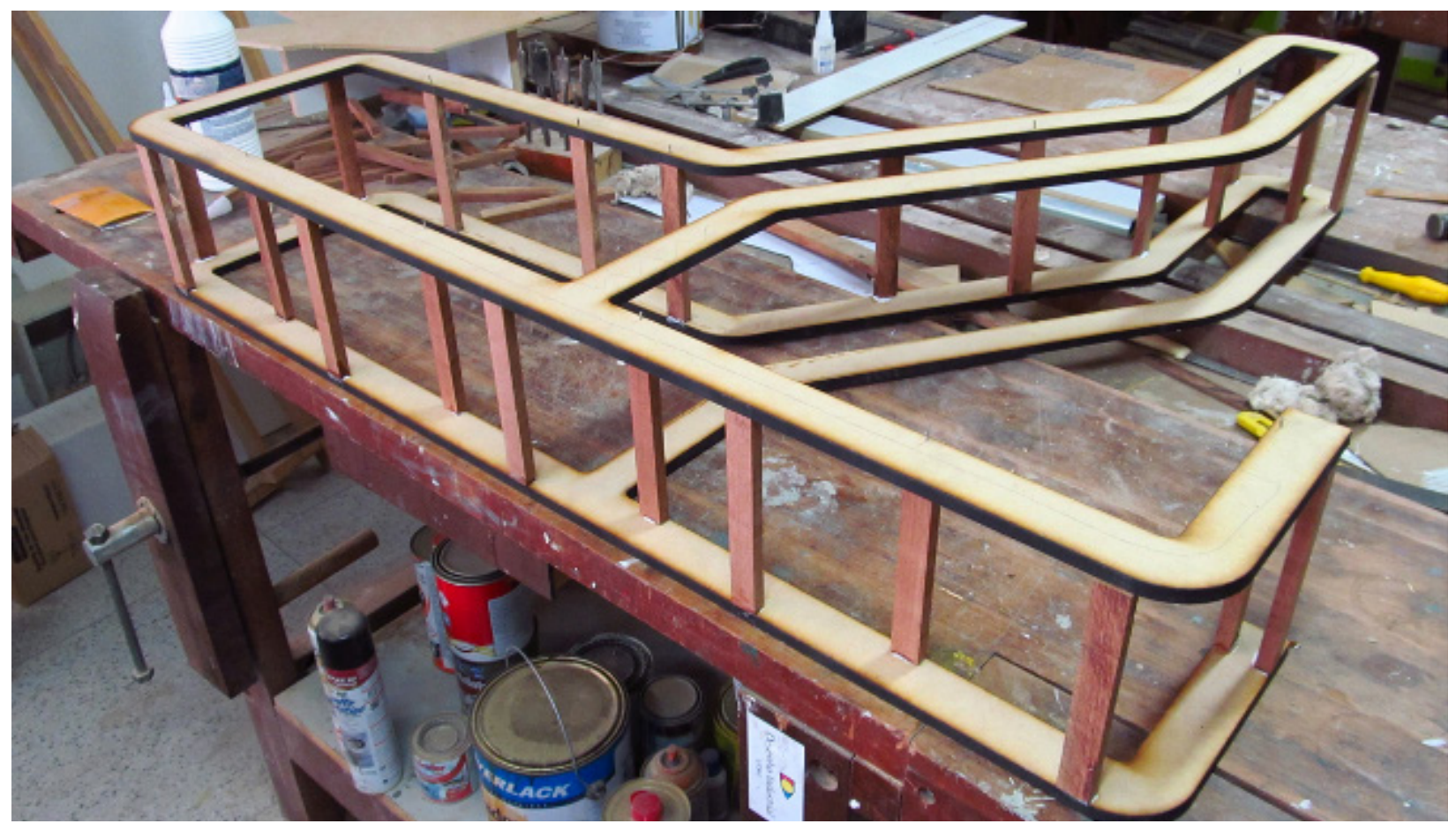

Figura 9 - Modelo do bebedouro em fase inicial de produção.

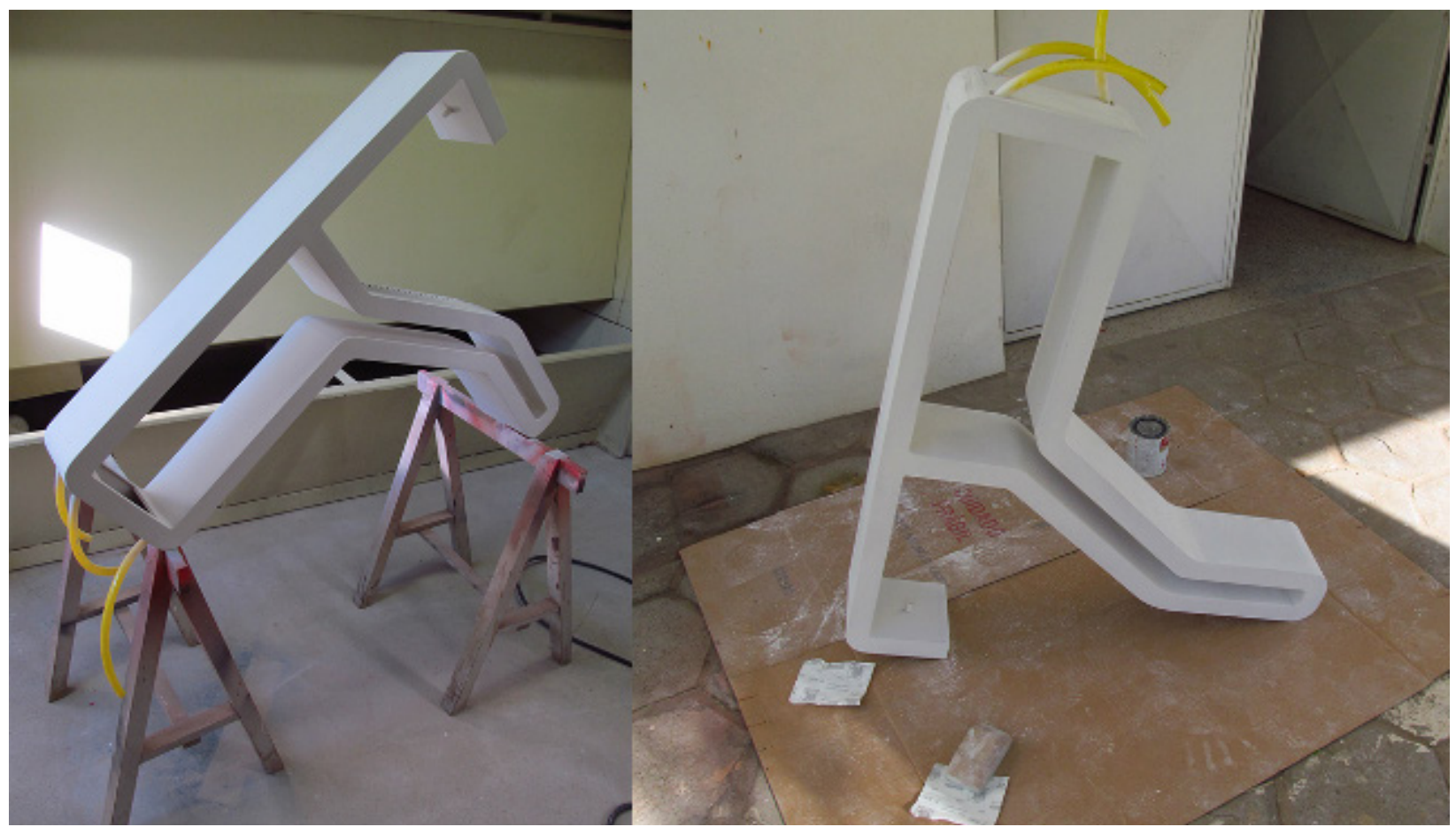

Figura 10 - Acabamentos finais do bebedouro.

\section{RESULTADOS}

Este trabalho alcançou os objetivos propostos com o projeto do bebedouro devidamente detalhado e especificado com os requisitos de projetos cumpridos e com a produção de um modelo funcional (Figura 11) em MDF e em tamanho real. 


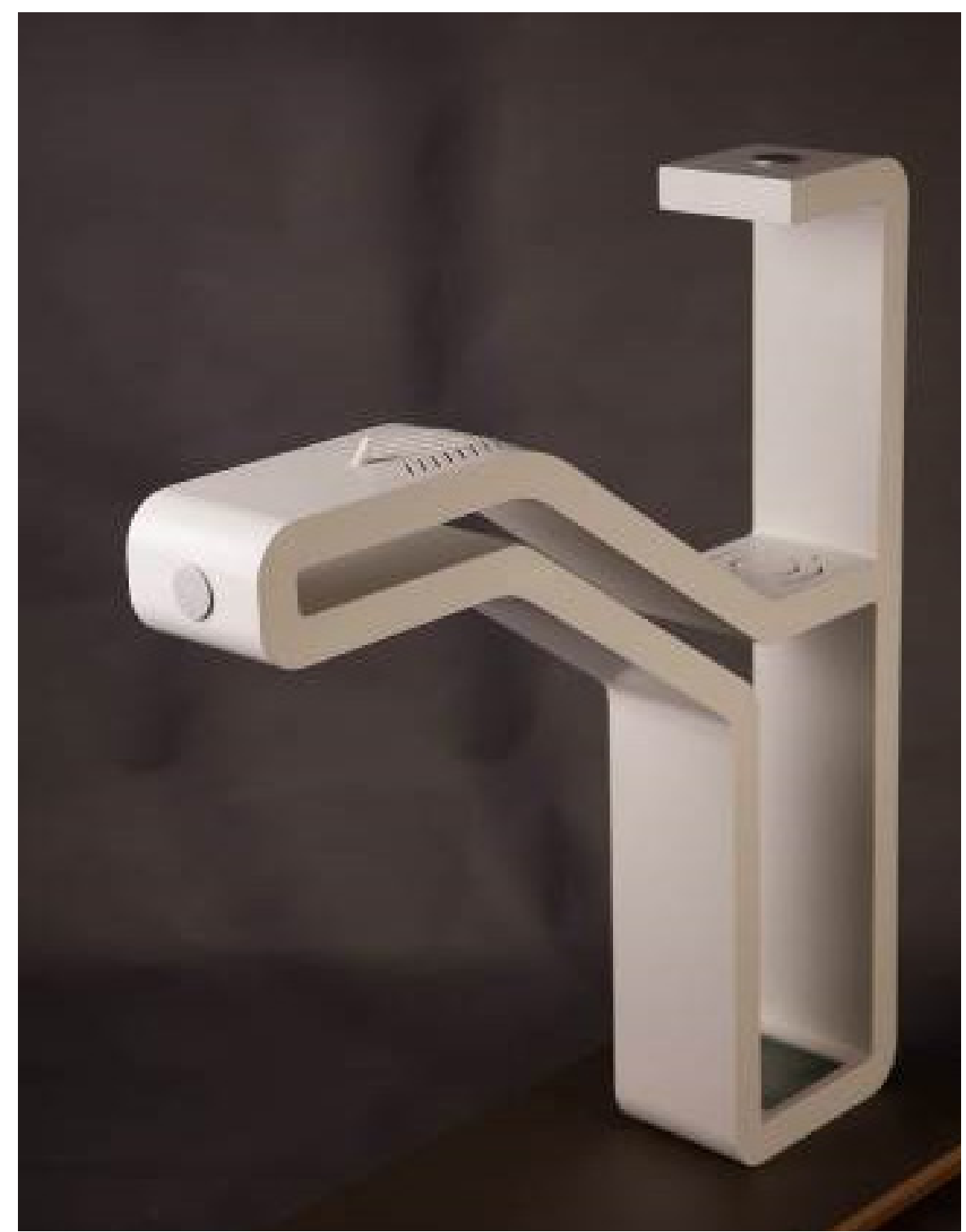

Figura 11 - Modelo funcional do bebedouro em tamanho real.

Criou-se um mobiliário urbano para suprir uma necessidade da população de Santa Maria - RS e ainda, com sua função adicional de encher copos e garrafas (Figura 12), pode incentivar as pessoas a levarem consigo diariamente uma garrafa de água, não descartável, para hidratação constante, tornando possível reenche-la quando estiverem fora de casa. Além do mais, é possível encher até garrafas de maior volume como uma garrafa de refrigerante de 3,3 litros. Tal característica foi assim pensada para aqueles que preferem utilizar garrafas maiores, até mesmo moradores de rua que às vezes só possuem recipientes assim. 


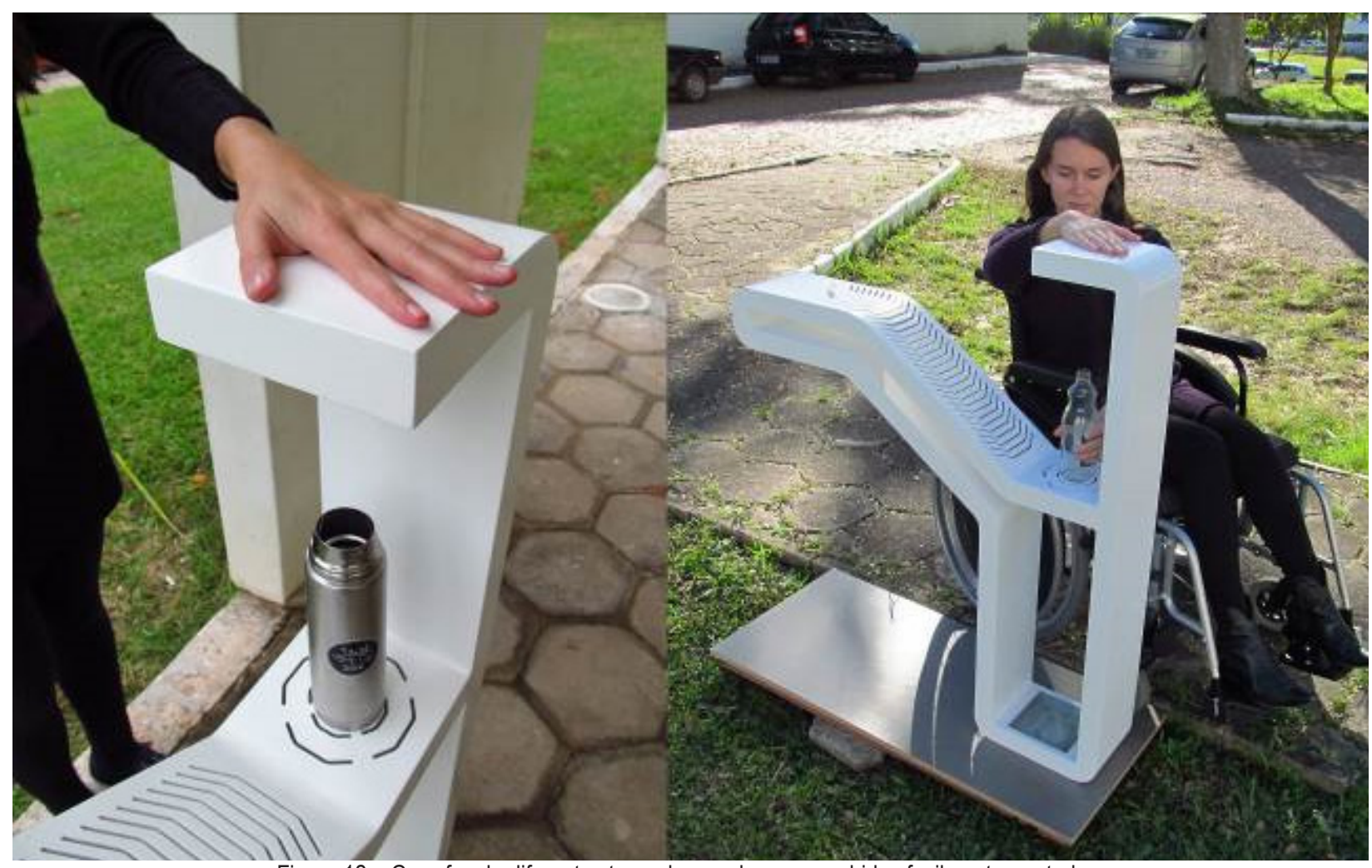

Figura 12 - Garrafas de diferentes tamanhos podem ser enchidas facilmente por todos.

Não fazendo distinções entre cadeirantes e não cadeirantes, o produto possui uma única saída de água em parábola com altura média, estipulada pela NBR9050/2004 da ABNT (2004) e também pela Lei Americana de Incapacitados (ADA - sigla em inglês, 2007), perfeitamente adequada aos dois grupos, oferecendo assim condições iguais de utilização do bebedouro (Figura 13 e Figura 14). Além disso, o acionamento do sistema para encher garrafas está também localizado em uma altura adequada para ambos os grupos.

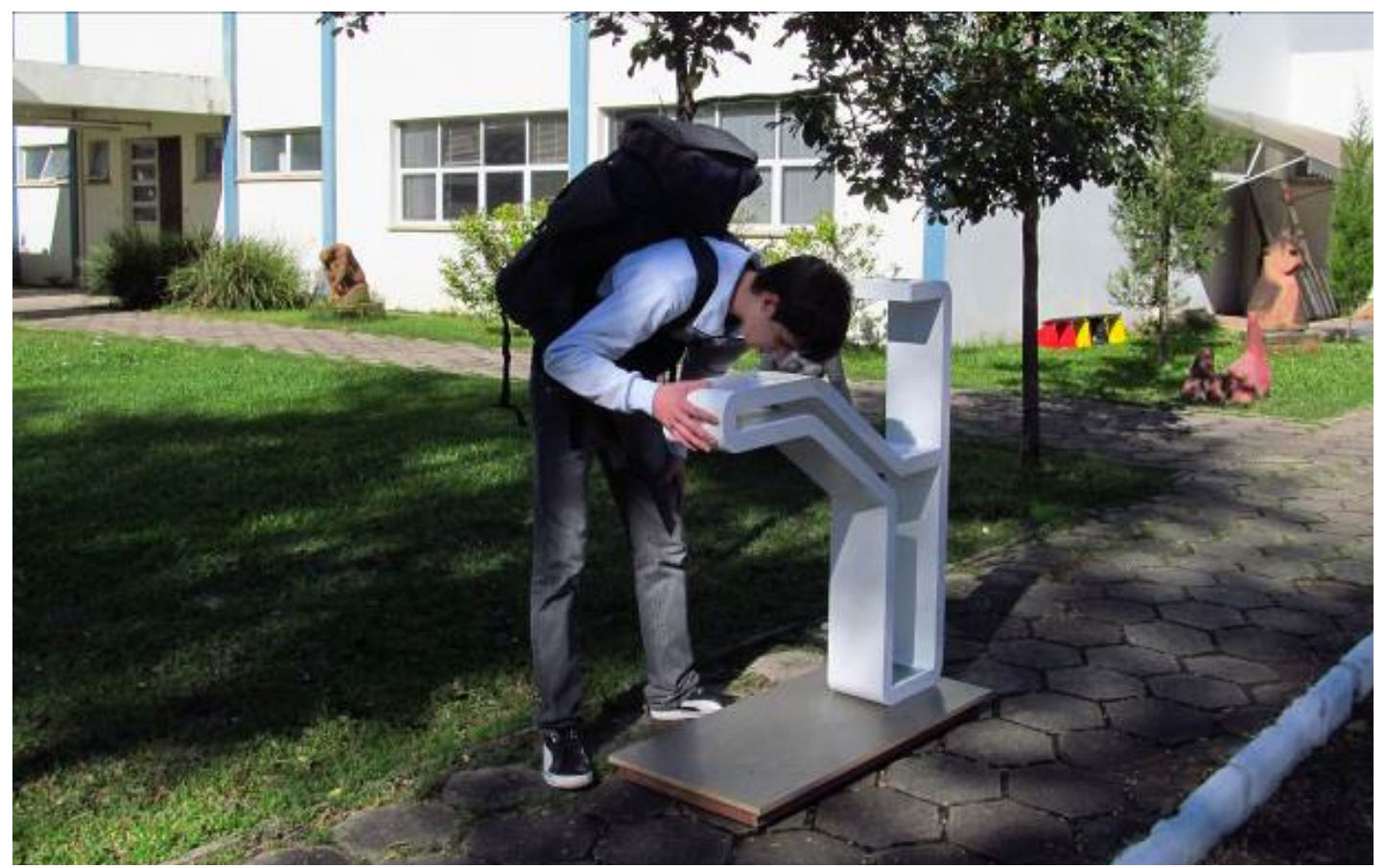

Figura 13 - Dimensões apropriadas para um uso confortável. 


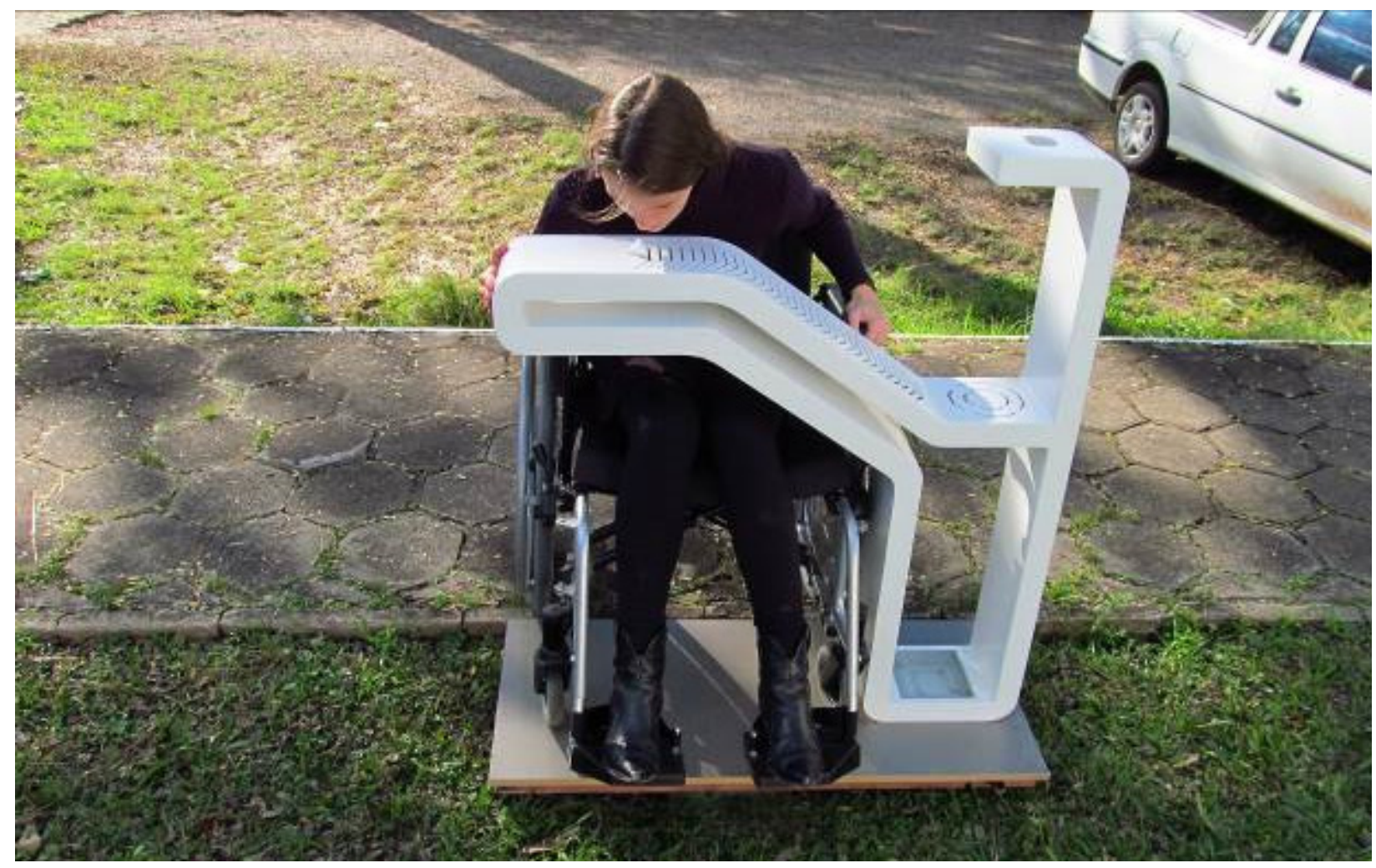

Figura 14 - Utilização adequada também para cadeirantes.

A partir da observação e testes de uso de alguns bebedouros, ficou claro que o usuário, seja ele jovem ou idoso, grande parte das vezes se apoia no bebedouro enquanto o utiliza. Pensando nisso, o produto criado oferece uma forma confortável e segura de apoio enquanto o usuário pressiona os botões de acionamento (Figura 15), botões estes que possuem também tamanho adequado para diminuir o esforço necessário para apertá-los.

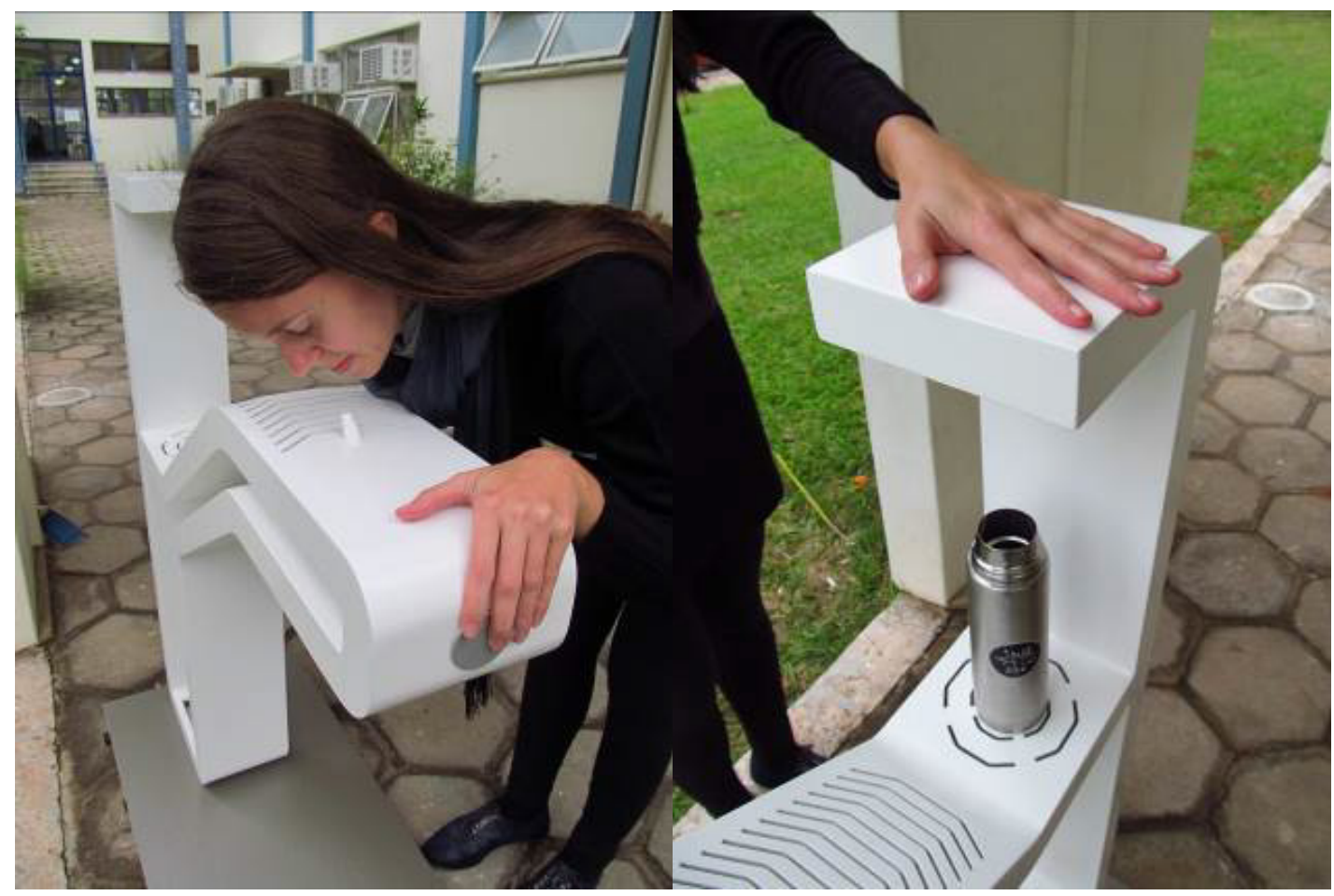

Figura 15 - Apoio confortável da mão enquanto aciona os botões do bebedouro. 
Completando sua segurança, a saída para beber água em parábola (Figura 16) é comprovadamente mais higiênica em comparação as saídas mais verticais, como visto em etapas anteriores do projeto.

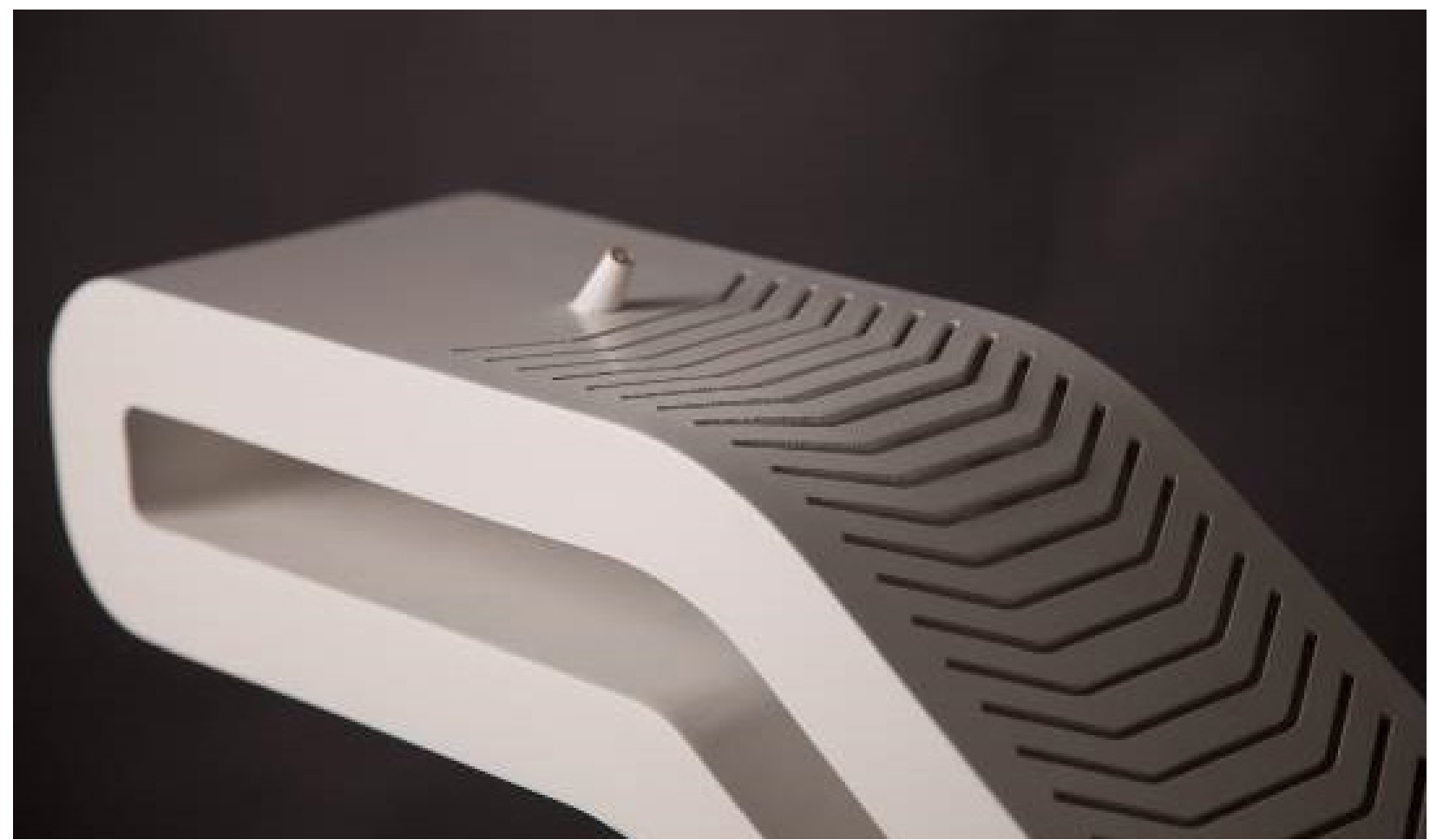

Figura 16 - Bico posicionado de forma que a água saia em parábola.

A iluminação instalada no produto (Figura 17) confere a ele o atributo de ser facilmente localizado e identificado em locais escuros. Essa característica, mesmo não sendo essencial, se mostra bastante útil já que diversos locais públicos são frequentados também a noite. 


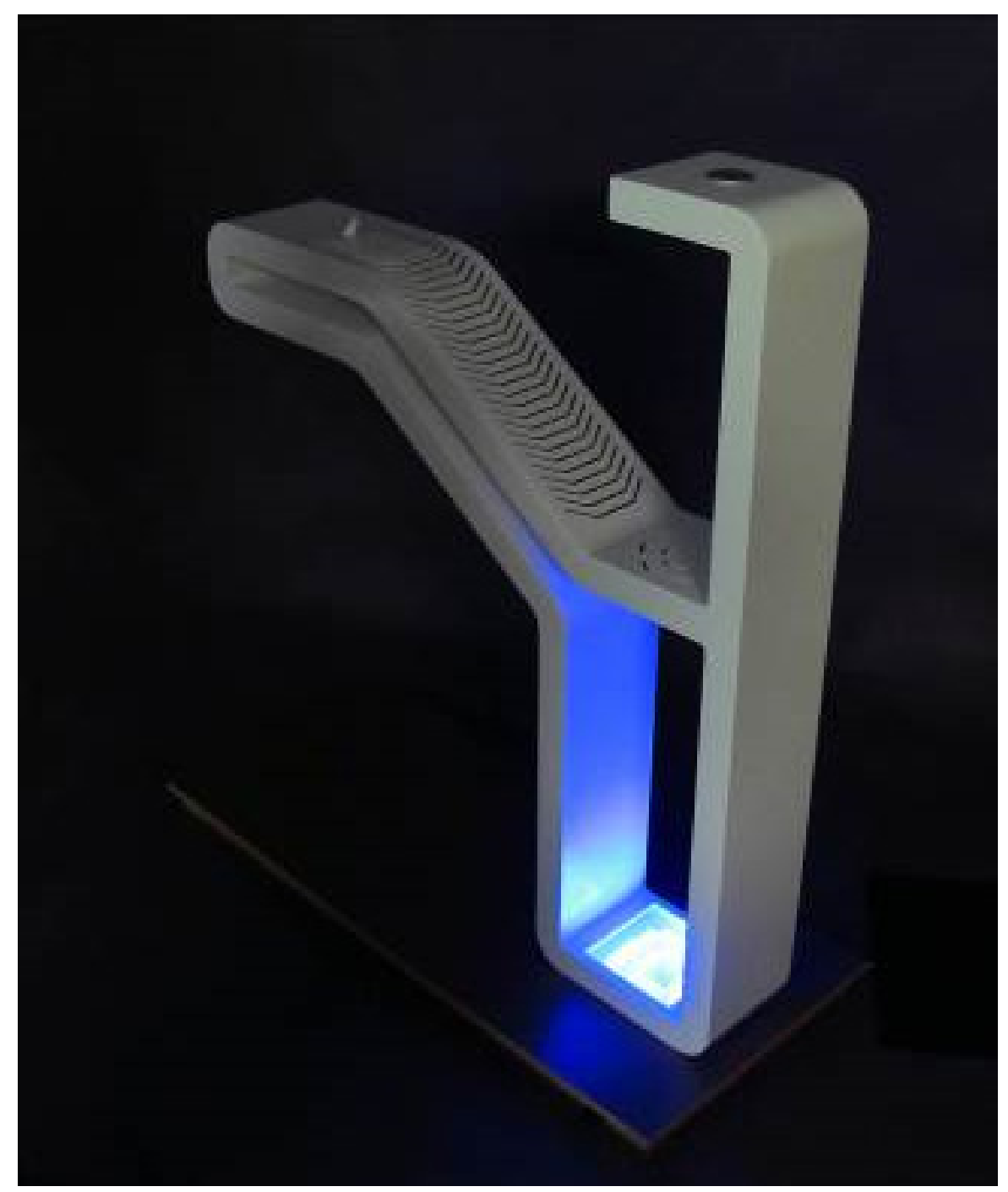

Figura 17 - lluminação de LED para identificação a noite em locais pouco iluminados.

Criou-se uma forma atemporal para o produto e que auxilia na condução do excesso de água para fora do bebedouro, exaltando a máxima "forma aliada a função" junto a referência estabelecida pelas pessoas entre a forma do bebedouro e a forma de uma torneira (Figura 18) o que colabora para o produto se tornar um ícone. Acredita-se que em um cenário onde o fornecimento público de água para beber fosse padronizado com a instalação de vários destes bebedouros, estes teriam potencial para criar uma boa e forte identidade do serviço prestado. Este cenário é possível pois diversas praças, parques e outros espaços públicos comportam a instalação deste produto. 


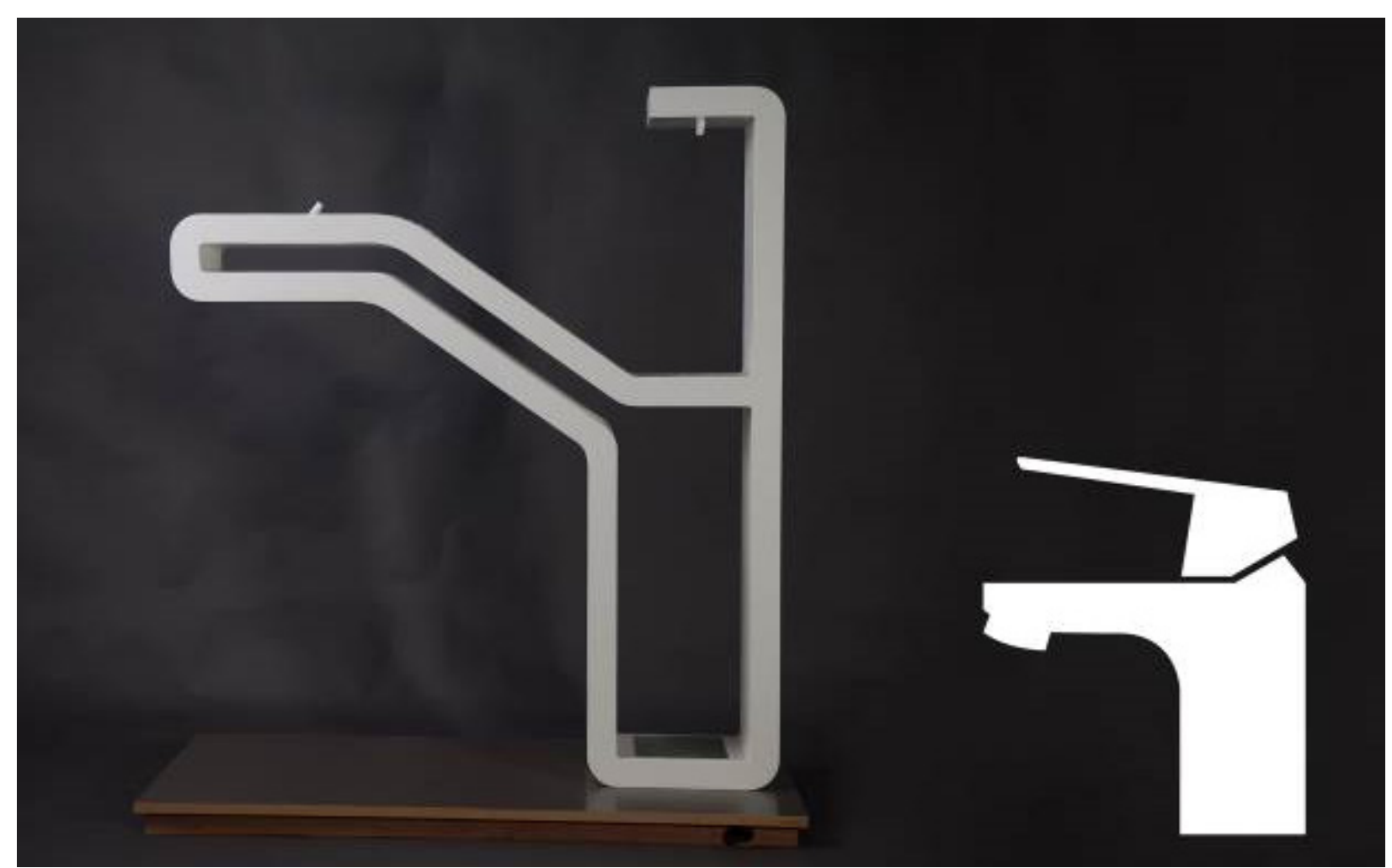

Figura 18 - A forma do bebedouro remete a uma torneira, o que facilita a sua identificação.

Devido a sua forma atemporal e diferentes possibilidades de materiais e acabamentos, mesmo sendo inicialmente pensado para o espaço aberto de Santa Maria, o produto ultrapassou os limites de seus requisitos e pode ser instalado não só no ambiente público urbano, mas também em residências, condomínios, empresas, escolas e outros, pois se adequa perfeitamente a diferentes espaços e usuários.

O produto já tem depósito de registro de desenho industrial junto ao Instituto Nacional da Propriedade Intelectual (INPI) e obteve notoriedade após ganhar cinco prêmios de Design e um de destaque como trabalho acadêmico, são eles:

- 1ㄴ Lugar

Prêmio Jovens Ideias 2014 | PUC/PR

- 1ㄴ Lugar

5ㅇ Prêmio Bornancini - Mobiliário Urbano (Estudante) | Apdesign

- 1ㄴ Lugar

Prêmio Tramontina de Design 2014 | Apdesign e Tramontina

- 1ㄴo Lugar

4ำ Prêmio SEBRAE Minas Design - Design de Impacto Social (Estudante) |

SE BRAE/MG

- 1ㄴ Lugar

Prêmio IED Brasil + Expo Milão 2015 - Design de Produto - Objetos para a Casa | Istituto Europeo di Design - Rio de Janeiro

- Vencedor

Prêmio "40 Melhores" da 29 Jornada Acadêmica Integrada da Universidade Federal de Santa Maria | UFSM 
O Bebedouro que já participou em 2014 de uma exposição em Curitiba, PR, em 2015 nas cidades do Rio de Janeiro, RJ e São Paulo, SP. Em função do prêmio IED Brasil, participou também do pavilhão brasileiro da Expo Milão 2015 na cidade italiana de Milão.

\section{REFERÊNCIAS}

ASSOCIAÇÃO BRASILEIRA DE NORMAS TÉCNICAS - ABNT. NBR 9050/2004: Norma Brasileira de Acessibilidade a edificações, mobiliário, espaço e equipamentos urbanos. Rio de Janeiro: ABNT, 2004.

BARATTO, Romullo. Dez propostas inovadoras de mobiliário urbano. Arch Daily. 12 maio 2013. Disponível em: <http://www.archdaily.com.br/br/01-113267/dez-propostas-inovadoras-de-mobiliario-urbano>. Acesso em: 30 mar. 2014.

BAXTER, Mike R. Projeto de produto: guia prático para o design de novos produtos. São Paulo: Blucher, 2000. ISBN 978-85-212-0265-5, pp. 61.

BONSIEPE, Gui. Metodologia experimental: desenho industrial. Brasília: CNPq, 1984.

INSTITUTO NACIONAL DE PROPRIEDADE INTELECTUAL - INPI. Guia Básico - Desenho Industrial. 10 mar. 2014. Disponível em: <http://www.inpi.gov.br/portal/artigo/ guia_basico_desenho_industrial>. Acesso em: 11 abr. 2014.

LÖBACH, Bernd. Design Industrial - Bases para a configuração dos produtos industriais. São Paulo: Edgard Blücher, 2001. ISBN 85-212-0288-1.

MOSCATELLI, Danielle. Mapas mentais e o desenvolvimento de projetos. Webinsider. 21 ago. 2013. Disponível em: <http://webinsider.com.br/2013/08/21/mapasmentais-e-o-desenvolvimento-de-projetos/>. Acesso em: 31 jan. 2014.

ROMANO, Fabiane Vieira. Modelo de Referência para o Gerenciamento do Processo de Projeto Integrado de Edificações. 2003, 326p. Tese - Programa de Pós-graduação em Engenharia de Produção, Universidade Federal de Santa Catarina, Santa Catarina, 2003.

SHAUKAT, Mobeen; RAMOS, Rafael; YEE, Adrien; REN, Yi. Redesign of Drinking Water Fountain. 2007.

TEIXEIRA, Filipa Isabel da Silva. Desenho do Espaço Público Urbano: Perspectivas Sócio-Espaciais. 2010. 75 f. Dissertação - Arquitetura Paisagista - Universidade Técnica de Lisboa, Lisboa, 2010. Disponível em: <https://www.repository.utl.pt/handle/10400.5/3115>. Acesso em: 30 mar. 2014. 